\title{
Can Financial Education Extend the Border of Bounded Rationality?
}

\author{
Doron Greenberg, Ze'ev Shtudiner \\ Department of Economics and Business Administration, Ariel University, Ariel, Israel \\ Email: zeevs@ariel.ac.il
}

Received 28 December 2015; accepted 12 February 2016; published 15 February 2016

Copyright (C) 2016 by authors and Scientific Research Publishing Inc.

This work is licensed under the Creative Commons Attribution International License (CC BY).

http://creativecommons.org/licenses/by/4.0/

(c) (i) Open Access

\begin{abstract}
When choosing a particular alternative from a number of financial assets, risk is an important feature. According to the classic Capital Assets Pricing Model (CAPM), we would expect to receive a positive correlation between risk and return of financial assets. However, studies show that investors judge financial assets in terms of "good" or "bad". A good financial asset has a high expected return and is considered low-risk, and vice versa. This type of thinking is biased, as it is both irrational and contradicts the classical theory of finance. One explanation for this bias is the affect heuristic. According to this heuristic, the investor forms her attitude about the asset in the first stage, and then links all of her subsequent judgments to this attitude. The aim of this study is to examine how this bias is affected by studying the CAPM in Finance entry courses. An experiment was conducted in which each subject made both risk judgments and return judgments in regard to 25 domestic stocks chosen randomly from the Tel Aviv 100 stock index. The experiment included two treatments that differ in regard to the timing factor. Some of the subjects were asked to judge the return and risk ratings before learning about the CAPM in class; the others were asked after studying the CAPM material. Finance education reduced the bias, but did not prevent it. The results show that in the teaching of Economics, there should be a balance between providing a coherent theoretical framework together with behavioral aspects. Moreover, given that finance education did not prevent the bias among students with background in quantitative analysis, it is reasonable to assume that other agents without this background would have more difficulties to apply the principles of investments under uncertainty.
\end{abstract}

\section{Keywords}

Experiment, Affect Heuristic, Familiarity Effect, CAPM 


\section{Introduction}

Since the crisis of 2008, there has been much discussion about the future of the economy, and especially about how the subject of finance should be taught. The collapse of the mortgage-backed securities raises a great need for either financial skills or more financial regulation. Willis [1] argues that "we will never find the effective financial education for which many search".

There are recent studies which indicate that financial education in higher education institutions can reduce present orientation, and risk aversion [2]-[4]. In this study, we analyze whether finance education can prevent cognitive biases in the capital market and lead to better decisions. More precisely, we examine the influence of studying the Capital Asset Pricing Model (CAPM) on biased risk and return judgments of financial assets. We show that even those who are highly educated with quantitative background have difficulties in applying financial models in their financial decisions.

The Sharpe [5] Lintner [6] CAPM is no doubt one of the cornerstones of financial economics. CAPM describes the relationship between risk and expected return, which is used in the pricing of risky securities. According to the classic model, we would expect in equilibrium to receive a positive correlation between risk and return. In other words, an asset which has a high risk also has a high return, and vice versa.

Actual risk and return judgments of financial assets can be biased. Using the known constraint of bounded rationality, people tend to obtain one input parameter and estimate the others. In estimating the other input parameters, one can use a perception based on the first input parameter [7] [8]. This perception can be an emotional heuristic method, defined as an affect heuristic [9] [10]. In regard to social judgments, the affect heuristic can be described as a tendency to "form an overall impression of another person as either good or bad on the basis of partial information, and then allow this global impression to influence subsequent judgments of the person” [11].

In competitive markets, such as financial markets, it is common that the main decision parameters-price versus quality and return versus risk-are contradictory. This suggests that people tend to make the wrong decision in competitive markets by assuming that the second input parameter strengthens the first. According to affect heuristic, assets are perceived on a continuum ranging from "good" to "bad". Judgments about risk and return are derived from this one-dimensional attitudinal continuum. If an asset is perceived as good, it will be judged to have both a high return and a low risk, whereas if it is perceived as bad, it will be judged as having both low return and high risk. Thus, we expect the correlation between risk and return judgments of unfamiliar assets to be negative.

Fischhoff et al. [7] study the perception of risk and benefit regarding smoking, alcoholic beverages, food additives, vaccines, antibiotics, X-rays, etc. They found that perceived risk and perceived benefit are negatively correlated for all of the above. In other words, it tends to be judged as having high risks and low benefits or as having low risks and high benefits. Given that the nature of benefit and risk for the above items are distinct, the above study suggest that the inverse relationship represents a kind of irrational thought based on previous experience or wishful thinking.

Alhakami and Slovic [12] found that this irrational thought is influenced by the strength of the affect associated with the activity. This suggests that: 1) If people like the activity, they perceive it as having high benefits and being low-risk, and vice versa; 2) if the first input parameter is perceived as good, then the second will also be perceived as good, and vice versa. Alhakamai and Slovic found that this causality goes in both directions, from benefit to risk and from risk to benefit.

Ganzach [13] found the same phenomena in the judgments of capital-market-analysts who judge return and risk for capital markets. It turns out that in regard to an unfamiliar capital market, the correlation between return and risk judgements were negative, while for a familiar market it was positive. Ganzach also found that the order is important: When subjects were asked about return first, their judgments were negatively correlated. However, when they were asked about risk first, their judgments were positively correlated. In another study, business students were asked to evaluate a number of industry groups represented on the New York Stock Exchange in terms of a set of judgmental variables [14]. After providing imagery and affective evaluations for each industry group, the participants judged the likelihood that they would invest in companies associated with each industry. Imagery and affective ratings were highly correlated with one another and with the likelihood of investing.

If perceptions about risk and return are the result, rather than the cause, of global preference, a natural question to ask is what determines global preference. One possibility is the mere-exposure effect, a psychological phenomenon by which people tend to develop a preference for things merely because they are familiar with 
them. In social psychology, this effect is called the familiarity effect. Subconsciously, individuals tend to minimize their cognitive load when making complex decisions that involve extensive learning processes [15]. Exposure to a previously unknown object makes this object more likable when prior knowledge reduces the load on cognitive processes that take place during the decision-making process [16]. In other words, familiarity reduces the complexity of mental processing, while the positive cognitive feeling of making an easier decision is misattributed to the object being rated.

The notion that people tend to express more positive emotions towards familiar objects and individuals is over a century old [17]. This topic first attracted the attention of the scientific community after Zajonc [18] published his seminal work, clearly demonstrating and explaining this phenomenon. This groundbreaking study was followed by hundreds of experiments conducted in various settings. The existence of the familiarity effect has been observed in virtually all types of decision-making processes. For example, familiarity may have an effect on corporate reputation [19]; brand awareness has an effect on product purchasing [20]; moreover, it also positively influences perceptions about the quality of products offered by online retailers [21].

Familiarity was also shown to affect preference in the analysis of financial data. In particular, a number of researchers have shown that investors prefer to invest in local stocks, a phenomenon labeled the home country bias (for a more detailed review, see Uppal [22]; Tesarand Werner [23]; Kilkaand Weber [24]). This phenomenon reflects the notion that investors put much more of their wealth into home assets than empirical optimizing models predict they should.

If perceptions about risk and return are biased, what can prevent this bias? Simply being told about biases rarely helps to notice and overcome them. Incentives, accountability (giving people the expectation that they will later have to explain their decision to others), training and group decision-making can reduce biases [25]. The aim of this study is to examine the effect of studying the CAPM in Finance entry courses on the affect heuristic in the capital market. The experiment design and procedure is detailed in Section 2. We discuss the results in Section 3, and Section 4 concludes.

\section{Experiment Design and Procedure}

The design of this experiment was a two group within-subject experiment. Each participant made both risk judgments and return judgments about 25 assets. The first group of subjects made risk judgments first, followed by return judgments, all on the same assets. The second group of subjects made return judgments first, followed by risk judgments. The 25 assets were domestic stocks. These stocks were chosen randomly from the Tel Aviv 100 stock index, traded on the Tel Aviv Stock Exchange (TASE). A total of 13 were familiar assets (stocks listed in the highest market capitalization on the exchange; those stocks are included in Tel Aviv 25 stock index), while12 were unfamiliar assets.

The experiment was conducted at Ariel University, Israel. The group of subjects included 209 students from the Departments of Economics and Business Administration in the Faculty of Social Science (students were in their second or third semester of studies) and 26 students from the Department of Industrial Engineering in the Faculty of Engineering in their fourth or fifth semester of studies (a total of 235 participants). All subjects had previously participated in at least two Economics courses and were taking the basic Finance course, a prerequisite for students in both groups.

A total of 127 subjects were asked to first judge the risk of these stocks, after which they were asked to judge the return. The second group was first asked to judge the return of these stocks, followed by the risk. This procedure was used in several previous studies [26]-[29]. The perceived risks and returns were measured on a single-item instrument. Participants were asked to rate risk and return on a numerical scale, ranging from 1 (very low) to 9 (very high). The experiment was conducted during class hours. Participation was voluntary.

The experiment included two treatments. A total of 108 subjects were asked to rate the return and risk ratings before studying the CAPM model; alternatively, 127 subjects were asked to rate the return and risk ratings after the model was studied in class.

\section{Results}

For each subject, the 25 risk judgments were correlated with the 25 return judgments. In agreement with the affect heuristic, the correlation average was negative: $r=-0.20(n=108, P<0.05)$. This result is consistent with the notion that global preference underlies both risk and return judgments of financial assets. This implies that 
an asset perceived as low-risk is also considered as having a high return. The global preference can be determined according to familiarity with the asset. According to the exposure effect, individuals tend to develop positive affect towards objects, individuals or, as in our case, financial assets, only because they are more familiar to them. This effect is reflected in our results: the correlation mean in absolute value for the familiar assets is significantly higher in comparison to the unfamiliar assets, -0.3567 and -0.2033 respectively $(n=96, P<0.05)$. This means that the bias was stronger when subjects made judgments about familiar assets.

We compared the mean correlation among subjects who made the judgments before studying the CAPM and the mean correlation among subjects who made the judgments after studying the CAPM model. The comparison was categorized according to familiar assets and unfamiliar assets, as displayed in Table 1. The mean correlations are negative both for subjects who made the judgments before studying the CAPM and for students who made the judgments afterwards. When the bias was strong, (familiar shares), the theoretical knowledge did not result in reducing the bias. However, the bias became significantly smaller when the subjects judged the risks and returns of unfamiliar shares.

Furthermore, we classified the subjects according to their individual correlations: significant negative correlation, significant positive correlation or insignificant correlation. Figure 1 displays the percentage of subjects

Table 1. Correlations between risk judgments and return judgments.

\begin{tabular}{cccc}
\hline & Familiar Assets & Unfamiliar Assets & P-Value (Familiarity) \\
\hline Before CAPM & -0.3567 & -0.2033 & $\mathrm{n}=99$ \\
After CAPM & $\mathrm{n}=102$ & -0.0066 \\
P-Value (Timing) & -0.2195 & $\mathrm{n}=109$ & 0.004 \\
\hline
\end{tabular}

Note: We used Fisher r-to-z transformation to test the difference between the correlations.

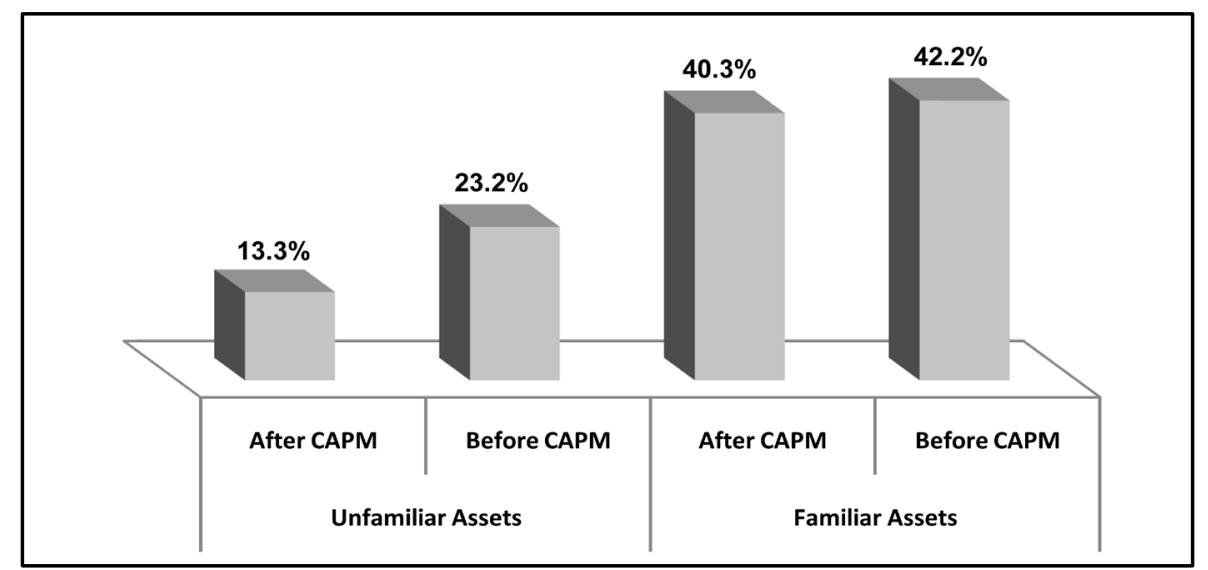

Note: subjects were classified according to their individual correlations. This figure displays the percentage of subjects with a significant negative correlation.

Figure 1. Percentage of subjects with a significant negative correlation.

Table 2. Correlations between risk judgments and return judgments (order effect).

\begin{tabular}{ccccc}
\hline Order & Timing & Familiar Assets & Unfamiliar Assets & P-Value (Familiarity) \\
\hline \multirow{2}{*}{ Return and then Risk } & Before CAPM & -0.516 & -0.179 & 0.005 \\
& After CAPM & -0.252 & 0.017 & 0.066 \\
& $P$-Value (Timing) & 0.058 & -0.223 & -0.033 \\
Risk and then Return & Before CAPM & -0.226 & -0.186 & 0.0495 \\
\hline
\end{tabular}

Note: We used Fisher r-to-z transformation to test the difference between the correlations. 
with a significant negative correlation. The figure displays similar results to those presented in Table 1 . The percentage of subjects who made irrational judgments about familiar assets is not influenced by studying the CAPM model. However, for unfamiliar assets, when the global preference is more difficult to determine, studying the model reduces the percentage of irrational subjects. Still, the percentage of subjects with irrational judgments is high even after studying the CAPM (Table 2).

\section{Conclusions}

The 2008 crisis and its consequences have provoked a great deal of discussion about the nature of how the subject of Finance is taught, and the possible need for reform. In class, for modelling purposes, an assumption of rational agents may be useful. However, it is clear that economic behaviour does not always accord with the tenets of classical rationality [30]-[32]. This study examined whether the border of bounded rationality can be extended by studying a theoretical model.

The specific phenomena that we examine is investors' tendency to base their judjments regarding risk and return on a global preference belief. According to this belief, good assets have high returns and are low-risk, and vice versa. This belief leads to a negative correlation between return and risk. Thus, it is biased in relation to the basic Finance models which, in eqilibrium, predict a positive correlation. Studying the model reduced the bias, but it did not prevent it. The results show that students need to have a broad and multi-faceted understanding of the financial reality. Even after the students have learned the model of investments under uncertainty, once the students switch from a finance class to a different framework in which the reurn and risk are not exhebited as embaded within the model, they had difficulty to recognize and to apply the theme of the model.

In finance education, there should be a balance between providing a coherent framework for building analytical skills, and the candid highlighting of uncertainty, the limits of economic knowledge, and the existence of serious alternative views and approaches. Moreover, given that finance education did not prevent the bias among students with background in quantitative analysis, it is reasonable to assume that other agents without this background would have more difficulties to apply the principles of investments under uncertainty.

\section{References}

[1] Willis, L.E. (2011) The Financial Education Fallacy. The American Economic Review, 101, 429-434. http://dx.doi.org/10.1257/aer.101.3.429

[2] Lahav, E., Rosenboim, M. and Shavit, T. (2015) Financial Literacy’s Effect on Elicited Subjective Discount Rate. Economics Bulletin, 35, A136.

[3] Shavit, T., Benzion, U., Shapir, O.M. and Galil, K. (2013) Are Time Preferences for Risky Outcomes, Riskless Outcomes and Commodities Really Different? Economics Letters, 118, 512-514. http://dx.doi.org/10.1016/j.econlet.2013.01.001

[4] Shavit, T., Lahav, E. and Rosenboim, M. (2016) Don’t Fear Risk, Learn about It: How Familiarity Reduces Perceived Risk. Applied Economics Letters. http://dx.doi.org/10.1080/13504851.2015.1133892

[5] Sharpe, W.F. (1964) Capital Asset Prices: A Theory of Market Equilibrium under Conditions of Risk. The Journal of Finance, 19, 425-442. http://dx.doi.org/10.1111/j.1540-6261.1964.tb02865.x

[6] Lintner, J. (1965) The Valuation of Risk Assets and the Selection of Risky Investments in Stock Portfolios and Capital Budgets. The Review of Economics and Statistics, 47, 13-37. http://dx.doi.org/10.2307/1924119

[7] Fischhoff, B., Slovic, P., Lichtenstein, S., Read, S. and Combs, B. (1978) How Safe Is Safe Enough? A Psychometric Study of Attitudes towards Technological Risks and Benefits. Policy Sciences, 9, 127-152. http://dx.doi.org/10.1007/BF00143739

[8] Simon, H.A. (1982) Models of Bounded Rationality: Empirically Grounded Economic Reason (Vol. 3). MIT Press, Cambridge.

[9] Slovic, P. (1987) Perception of Risk. Science, 236, 280-285. http://dx.doi.org/10.1126/science.3563507

[10] Slovic, P. (2007) Perception of Risk from Asteroid Impact. In: Bobrowsky, P.T. and Rickman, H., Eds., Comet/Asteroid Impacts and Human Society: An Interdisciplinary Approach, Springer-Verlag, Berlin, 369-382. http://dx.doi.org/10.1007/978-3-540-32711-0_22

[11] Perlman, D. and Cozby, R.C. (1983) Social Psychology. Holt, Rinehart \& Winston, New York.

[12] Alhakami, A. and Slovic, P. (1994) A Psychological Study of the Inverse Relationship between Perceived Risk and Perceived Benefit. Risk Analysis, 14, 1085-1096. http://dx.doi.org/10.1111/j.1539-6924.1994.tb00080.x 
[13] Ganzach, Y. (2000) Judging Risk and Return of Financial Assets. Organizational Behavior and Human Decision Processes, 83, 353-370. http://dx.doi.org/10.1006/obhd.2000.2914

[14] MacGregor, D.G., Slovic, P., Dreman, D. and Berry, M. (2000) Imagery, Affect, and Financial Judgment. The Journal of Psychology and Financial Markets, 1, 104-110. http://dx.doi.org/10.1207/S15327760JPFM0102_2

[15] Adler, M. (1985) Stardom and Talent. American Economic Review, 75, 208-212.

[16] Dechene, A., Stahl, C., Hansen, J. and Wanke, M. (2009) Mix Me a List: Context Moderates the Truth Effect and the Mere-Exposure Effect. Journal of Experimental Social Psychology, 45, 1117-1122. http://dx.doi.org/10.1016/j.jesp.2009.06.019

[17] Titchener, E.B. (1910) A Textbook of Psychology. New York, Macmillan.

[18] Zajonc, R.B. (1968) Attitudinal Effects of Mere Exposure. Journal of Personality and Social Psychology, 9, 1-27. http://dx.doi.org/10.1037/h0025848

[19] Brooks, M. and Highhouse, S. (2006) Familiarity Breeds Ambivalence. Corporate Reputation Review, 9, 105-113. http://dx.doi.org/10.1057/palgrave.crr.1550016

[20] Hoyer, W.D. and Brown, S.P. (1990) Effects of Brand Awareness on Choice for a Common, Repeat-Purchase Product. Journal of Consumer Research, 17, 141-148. http://dx.doi.org/10.1086/208544

[21] Griffith, D.A. and Gray, C.C. (2002) The Fallacy of the Level Playing Field: The Effect of Brand Familiarity and Web Site Vividness on Online Consumer Response. Journal of Marketing Channels, 9, 87-102. http://dx.doi.org/10.1300/J049v09n03_05

[22] Uppal, R. (1992) The Economic Determinants of Home Country Bias in Investors' Portfolios. Journal of International Financial Management and Accounting, 4, 171-189. http://dx.doi.org/10.1111/j.1467-646X.1992.tb00028.x

[23] Tesar, L.L. and Werner, I.M. (1992) Home Bias and the Globalization of Securities. NBER Working Paper No. 4218.

[24] Kilka, M. and Weber, M. (1997) Home Bias in International Stock Return Expectations. Working Paper, University of Mannheim, Mannheim.

[25] Larrick, R.P. (2004) Debiasing. In: Koehler, D.J. and Harvey, N., Eds., Blackwell Handbook of Judgment and Decision Making, Blackwell Publishing, Hoboken, 316-338. http://dx.doi.org/10.1002/9780470752937.ch16

[26] Slovic, P. (1967) The Relative Influence of Probabilities and Payoffs upon Perceived Risk of a Gamble. Psychonomic Science, 9, 223-224. http://dx.doi.org/10.3758/BF03330840

[27] Payne, J.W. (1975) Relation of Perceived Risk to Preferences among Gambles. Journal of Experimental Psychology: Human Perception and Performance, 1, 86-94. http://dx.doi.org/10.1037/0096-1523.1.1.86

[28] Weber, E.U., Anderson, C.J. and Birnbaum, M.H. (1992) A Theory of Perceived Risk and Attractiveness. Organizational Behavior and Human Decision Processes, 52, 492-523. http://dx.doi.org/10.1016/0749-5978(92)90030-B

[29] Weber, E.U. and Milliman, R.A. (1997) Perceived Risk Attitudes: Relating Risk Perception to Risky Choice. Management Science, 43, 123-144. http://dx.doi.org/10.1287/mnsc.43.2.123

[30] Klein, G. and Shtudiner, Z. (2015) Trust in Others: Does It Affect Investment Decisions? Quality and Quantity, 49, 1-19. http://dx.doi.org/10.1007/s11135-015-0245-6

[31] Shtudiner, Z., Klein, G. and Kantor, J. (2016) Who Is Responsible for Economic Failures? Self-Serving Bias and Fundamental Attribution Error in Political Context. Quality and Quantity, 50, 1-16. http://dx.doi.org/10.1007/s11135-015-0307-9

[32] Kantor, J., Shapir, O. and Shtudiner, Z. (2015) Beauty Is in the Eye of the Employer: Labor Market Discrimination of Accountants. http://dx.doi.org/10.2139/ssrn.2655407 